\title{
Posible simbolismo funerario de fragmentos cerámicos en Egipto
}

\author{
María José López GrandE*
}

\section{SUMMARY}

In the spiritual life of the ancient Egyptians, the mud of the Nile as well as the water and the river's flood had an important meaning of life and regeneration. The god Jnum made the humanity in his potter-wheel with the clay of the Nile's mud, and the meaning of life and regeneration could be transfered, as a logical extension of this belief, to some kind of pottery vessels. Those vessels and fragments of them were used with funerary purpose, sometimes as offerings and even as fictitious coffins in modest burials.

Las crecidas del Nilo y las consecuentes inundaciones de su valle favorecieron el nacimiento y desarrollo de la civilización egipcia. Periodicamente la tierra de Egipto quedaba cubierta por una espesa capa de agua y lodo que el Nilo aportaba. Poco a poco el agua se desecaba y el río volvía a su cauce. El lodo, sin embargo, permanecía sobre la tierra; paulatinamente se unía a ella y la enriquecía ?.

Aquel barro hacía posibles los cultivos. En sus charcas abundaban las ranas y otros pequeños animales, y los egipcios vieron en aquel fango una fuente de vida y abundancia. Era un lodo blando cuando estaba húmedo, y duro y resistente cuando se secaba. Se utilizaba para hacer los adobes ${ }^{2}$ con los que se edificaba, y modelado servía para

* Universidad Autónoma de Madrid

Herodoto, II.5; J. G. GRIFFITHS, "Hecateus and Herodotus on "A Gift of the River" JNES 25 (1966) pág. 57.

z A. J. SPENCER, Brick Architecture in Ancient Egypt. Warminster 1979, pág. 3 
"construir en pequeño». De ello se ocupaban los alfareros, llamados en egipcio $i K d(w) n \underline{d} s(t)^{3}$ que hacían recipientes para todos los usos ${ }^{4}$ e incluso fabricaban miniaturas de casas y de ofrendas que serían utilizadas en la eternidad 5 .

El dios Jnum también trabajaba el barro y modelaba a los hombres en su torno de alfarero ${ }^{6}$; aquella era la idea egipcia que explicaba el origen de la humanidad.

Se trataba de una noción antigua a la que ya se alude en los Textos de las Pirámides ${ }^{7}$, un concepto que aparece de forma reiterada en la literatura egipcia de casi todos los períodos ${ }^{8}$ y que se documenta sin interrupción en los documentos iconográficos desde el reinado de Hatshepsut hasta el final de la historia del antiguo Egipto ${ }^{\text {. }}$.

La arcilla aluvial que proporcionaba el lodo del Nilo ${ }^{10}$ no era otra cosa que el propio lodo depurado. En estado natural -barro- era abundante

3 Literalmente "constructores en pequeño». Véase A. H. GARDINER, Ancient Egyptian
Onomastica, Vol. I. Oxford 1947, págs. 72-73.
4 C. HoPE, Egyptian Pottery. Haverfordwest 1987, págs. 47-52; J. BouRRIAU, Umm El-Gaag.
Pottery from the Nile Valley Before the Arab Conquest. Cambridge 1981, passim.
5 Véanse, por ejemplo, British Museum, EA-35505: D. Radal -Maciver- A. C. MACE, El
Amra and Abydos 1899-1901. London 1902, pág. 42, PI. X, 1-2; British Museum, EA-32609: E.
Roik, Das Altägyptische Wohnhaus und seine Darstellung im Flachbild. Frankfurt am Main 1988,
Teil 2, abb. 77. Otros ejemplos en Ibidem, abb. 70-83.
6 Acerca del dios Jnum véase: A. M. BADAWY, Der Gott Chnum. Glückstadt-Hamburg-New
York, 1937; LÄ I, 950-954; G. MOKHTAR, «Similarity between the Ram Gods of Ehnasya and Elephantine» MDAIK 47 (1991) págs. 253-254.

7 Pyr. 324 (524a); R. O. Faulknen, The Ancient Egyptian Pyramid Texts. Oxford 1969, pág. 103.

\& Imperio Antiguo-Imperio Medio: Pyr. 324 (524a); 294 (437a-c); "Himno al Nilo", Papiro Sallier II, XII (British Museum 10182) y otras fuentes en D. VAN DER PLAS, L'Hymne a la crue du Nil. Leiden 1986, Vol. I, pág. 26; Vol. II, págs. 28-29; Papiro Leiden I. 344 recto, 2, 4 «Las admoniciones del sabio Ipuer»: A. H. Gardiner, The Admonitions of an Ancient Egyptian Sage, from Hieratic Papyrus in Leiden. Leipzig 1909, pág. 24, véase además la bibliografía citada por R. PARKINSON, en "Teachings, Discourses and Tales for the Middle Kingdom", S. QuIRKE (ed.) Middle Kingdom Studies. Whitstable 1991, documento XVI en págs. 112-113.

Imperio Nuevo: una posible mención en el Papiro Westcar (Papiro Berlín 3033, 9.27): A. ERMAN, Die Märchen des Papyrus Westcar (Berlín 1890), pág. 60, Lám. X; H. GoEdickE, "Radjet's Delivery" VA 1 (1985) págs. 24-26; Papiro British Museum 10474 "Las enseñanzas de Pathhotep", XII-15-16: E.A.W. Budge, Facsimiles of Egyptian Hieratic Papyrus in the British Museum. Second Series. London 1923, pág. 13, PI. Vl; «El cuento de los dos hermanos», Papiro D'Orbiney (British Museum 10183, 9.6): A. H. Gardiner, Late-Egyptian Stories (Bibliotheca Aegyptiaca I) Bruxelles 1932, pág. 19.

Época tardía: numerosas menciones en los textos del templo de Jnum en Esna, quizá el santuario más importante que el dios tuvo en Egipto. Véase: S. SAUNERON, Esna. 5 Vols. Le Caire 1959-1969, passim. Acerca del determinativo de alfarero utilizado en dichos textos, Ibidem. Vol. II, pág. XXIV.

9 R. Holthoer, New Kingdom Pharaonic Sites. The Pottery (The Scandinavian Joint Expedition to Sudanese Nubia. Vol. 5:1). Lund 1977, págs. 5-26, figs. 1-40.

10 En Egipto también se emplearon en alfareria arcillas margosas que se obtenian de tierras de las zonas desérticas. Acerca de la obtención de ambos tipos de arcilla en Egipto, véase: D. 
en el valle, pero no por ello menospreciado ${ }^{11}$. Formaba parte de la tierra negra de Egipto $(K m t)$, la única en el país nutrida por la crecida del Nilo y suceptible de ser cultivada ${ }^{12}$.

El lodo del Nilo encerraba la potencialidad de la vida y en nuestra opinión esa propiedad no quedaba limitada al barro. Atendiendo a la lectura de algunos textos egipcios y a la observación de un hecho arqueológico, creemos poder asegurar que aquella propiedad, poseer la potencialidad de la vida, se transmitía del barro a la arcilla que éste proporcionaba, e incluso a la cerámica que se elaboraba a partir de la arcilla.

En ese sentido queremos llamar la atención sobre un pasaje de los Textos de las Pirámides que se repite dos veces consecutivas y en el que podemos leer:

"Yo (Unas) he salido de mi jarra dnit después de haber pasado la noche en mi jarra dnit, y apareceré en la mañana» ${ }^{13}$.

El pasaje fue puesto en relacion por S. Hassan ${ }^{14}$ con uno de los procesos de la momificacion - la inmersion en un baño de sales en la que el cuerpo del difunto se purificaba- que en opinion de W.R. Dawson tenía lugar en el interior de un gran recipiente ${ }^{15}$. El texto alude sin duda a la renovación de la vida que se aseguraba en la mentalidad egipcia mediante la preservación del cuerpo a la que la momificación estaba encaminada, y que de acuerdo a ciertas ideas egipcias de ultratumba tenía lugar en la reaparición del sol cada mañana, una vez superados los peligros de la noche ${ }^{16}$.

En el pasaje citado, Unas se dispone a alcanzar la mañana después de haber permanecido el tiempo de la noche en el interior de un recipiente cerámico ${ }^{17}$. El dato es interesante, ya que si bien la cultura egipcia

ARNOLD «Techniques and Traditions of Manufacture in the Pottery of Ancient Egypt», en D. ARNOLD - J. Bouraiau (ed.) An Introduction to Ancient Pottery. Mainz am Rhein 1993, págs. 11-12.

11 Ibidem.

12 Papiro Sallier II, XI, y otras fuentes, en D. VAN DER PLAS, op. cit., Vol. I, págs. 20-21; Vol. II, págs. 8-9. Es la misma arcilla que hoy sigue utilizándose en Egipto: F. QUESADA SANZ - M. J. LóPEZ GRANDE, «Talleres y producciones cerámicas actuales en Egipto: un estudio etnoarqueológico en Heracleópolis Magna". BAEO 24 (1988) págs. 325-355.

13 Pyr. 294 (437a-d); R. O. FaUlkner, op. cit., pág. 88.

14 Excavations at Giza, Vol. IV (1932-33). Cairo 1943, pág. 87.

15 «Making a Mummy». JEA 13 (1927) págs. 44-45. PI. XVI, b.

16 A. J. Spencer, Death in Ancient Egypt. Aylesbury 1982, págs. 139-164; J. TAYLOR, Egyptian Coffins. Aylesbury 1989, págs. 8-9.

17 La identificación de la jarra dnit con un vaso cerámico de grandes dimensiones fue sugerida hace ya años por A. HaMADA que reconoció en la palabra dnit una forma arcaica de la denominación de grandes jarras cerámicas dnt a las que se alude en una estela de Ramses II (Estela 34504 del Museo Egipcio de El Cairo). Véase: A. Hamada, "A Stela from Manshiyet Es-Sadr" ASAE 38 (1938) pág. 229, n. 4; KRI 362-367; PMIV, pág. 62. 
sobresalió entre otras cosas por el empleo de ataudes y sarcófagos magníficos, receptáculos ideados para albergar y preservar de la destrucción los cuerpos momificados ${ }^{18}$, no hay que olvidar que su uso estuvo limitado a los sectores más favorecidos de la sociedad. La madera y la piedra con la que se fabricaban eran materiales poco asequibles ${ }^{19}$ y en ocasiones fueron sustituidos por una materia mucho más económica: la arcilla. Su empleo en la elaboración de recipientes ideados para alojar cuerpos humanos durante toda la eternidad, no es determinante para establecer la capacidad económica de quienes utilizaron dicha práctica funeraria. No obstante, en algunos casos el factor económico parece haber sido decisivo para su empleo ${ }^{20}$.

\section{CONTENEDORES DE ARCILLA PARA LOS MUERTOS}

\section{SARCÓFAGOS DE ARCILLA}

En arcilla se modelaron sencillas cajas rectangulares que a modo de sarcófagos fueron utilizadas en época predinástica y durante las primeras dinastías ${ }^{21}$. Esa práctica funeraria parece abandonarse, o al menos no está documentada, desde los inicios del Imperio Antiguo y hasta los últimos momentos del Segundo Período Intermedio ${ }^{22}$. A partir de ese período comienzan a documentarse sacórfagos antropoides de arcilla que han sido considerados por L. Kuchman como una práctica funeraria propia de Egipto que no responde a influencias externas, a pesar de los paralelos muy próximos que se documentan en Canaán en fechas similares ${ }^{23}$.

18 De ahí el nombre alegórico que el sarcófago recibió en el Imperio Antiguo: $n b{ }^{c} n j$ (= «Señor de la vida"), $W b \mid 199,14 ; L \ddot{A} \vee 471-485$.

19 Véase como ejemplo, referido a época ramésida, J. J. Janssen, Commodity Prices from the Ramessid Period. Leiden 1975, págs. 215-248.

${ }^{20}$ L. KuChmaN, “Egyptian Clay Anthropoid Coffins». Serapis 4 (1977-78) págs. 15-19.

${ }_{21}$ Véase, por ejemplo, D. RANDAL - MACIVER-A. C. MACE, op. cit., pág. 10, PI. II, 6; Ayrton -W.L.S. Loat, Pre-Dynastic Cemetery at El Mahasna. (Egypt Exploration Fond. Memoir 31) London (sin fecha de publicación) pág. 20, PI. VII, 38; T.E. Peet, The Cemeteries of Abydos, II (1911-1912). London 1914, pág. 14, PI. I, 1; T. E. Peet-W.L.S. Loat, The Cemeteries of Abydos III (1912-1913). London 1913, págs. 14-15, Pl. I, 5; W.M.F. Petrie- J.E. Quibell, Nagada and Ballas 1895. London 1986, págs. 3, 13-14, PI. III.

${ }_{22}$ SPI en lo sucesivo; L. KuCHMAN, Serapis 4 (1977-78), pág. 13.

${ }^{23}$ L. Kuchman, Serapis, 4 (1977-78) pág. 20. J. N. TuBb y R. L. Chapman atribuyen a individuos pertenecientes a los llamados «pueblos del mar» el empleo de sarcófagos de arcilla e incluso el uso de dos grandes recipientes como "contenedores parciales» del difunto en algunos enterramientos documentados en Tell-es-Sa'iyideh (Jordania): Archaeology and the Bible. London 1990 (ed. 1991) págs. 74-75. 
Dichos sarcófagos tienen forma de caja alargada, realizada en un solo bloque, con una amplia abertura en uno de los lados de su cara superior por la que el difunto era introducido y acomodado. Después la oquedad se cerraba con una pieza también de cerámica que en ocasiones podía incluir la indicacion de las facciones del rostro ${ }^{24}$, a veces con un modelado muy conseguido de la imagen representada ${ }^{25}$. Algunos sarcófagos marcaban incluso las extremidades superiores cruzadas, modeladas sobre el pecho, a veces con los senos indicados ${ }^{26}$; otros detalles se indicaban con policromía e incluso en ocasiones la caja se decoraba por completo con imágenes pintadas e inscripciones ${ }^{27}$.

El uso de los sarcófagos de arcilla se documenta en Egipto a lo largo de todo el Imperio Nuevo ${ }^{28}$ en el Delta, en Nubia y en el Egipto Medio, y durante el Tercer Período Intermedio ${ }^{29}$ con una dispersión similar ${ }^{30}$. Su uso parece hacerse más frecuente a partir de época saíta, y se conocen importantes grupos de enterramientos en sarcófagos de arcilla en época ptolemaica y romana ${ }^{31}$. Esos sarcófagos de época más tardía incluyeron en ocasiones en el exterior de su superficie superior imágenes propiciatorias modeladas también en arcilla que favorecerían al difunto en la eternidad ${ }^{32}$.

\section{RECIPIENTES CERÁMICOS}

Los enterramientos en el interior de recipientes cerámicos se documentan en Egipto en momentos predinásticos y durante las primeras dinastías ${ }^{33}$. A veces el cuerpo yacía sobre el suelo de la tumba o sobre un recipiente cerámico y se cubría total o parcialmente con un gran cuenco

\footnotetext{
${ }^{24}$ W. M. F. Petrie-Duncan, J. G., op. cit., págs. 17, PI. XVII-A, 4; 16, PI. XII-C. 23; 18, PI. XIX310.

W. M. F. Petrie, Gizeh and Rifeh. Loncion 1907, pág. 22, PI. XXVII, 1-2.

${ }^{25}$ G. SteindorfF, Aniba, Vol. II, Tafel 39-40.

${ }^{27}$ L. Kuchman, Serapis, 4 (1977-78) pág. 14; W. M. F. Petrie- J. G. Duncan, Hiksos and Israelite Cities. London 1906, págs. 16-17, PI. XV-XVA.

28 En lo sucesivo IN.

29 En lo sucesivo TPI.

30 L. Kuchman, Serapis, 4 (1977-78) págs. 14-17.

${ }^{31}$ lbidem, págs. 17-19.

32 Por ejemplo la imagen de Bes sobre la tapa de un sarcófago infantil hallado en Abidos y datado por Ayrton en un momento impreciso posterior a la XIX dinastía: E. R. AYRTON -M.A. Curreliy- A.E.P. Wejgall, Abydos III, 1904. London 1904, págs. 1, 51-52, PI. XXIII, 6; pág. 52, PI. XXVIII, 5-6.

33 D. Randal-Maciver- A.C. Mace, op. cit, págs. 10-14, PI. II; E.R. Ayrton- M.A. Curely;A.E.P. WeIGALL, op. cit., pág. 47, PI. VI.
} 
también cerámico colocado en forma invertida. Esa práctica funeraria fue denominada «enterramientos bajo recipientes invertidos» por Peet y Loat que la documentaron en Abidos ${ }^{34}$.

Hasta ahora se ha estimado que el uso de recipientes cerámicos como contenedores de difuntos no fue frecuente en Egipto en momentos posteriores, si bien en época dinástica (SPI, IN y TPI) fue una práctica funeraria utilizada en enterramientos infantiles ${ }^{35}$. Ese tipo de enterramiento infantil ha sido compartido por diferentes culturas en diferentes períodos, y está bien atestiguado en Canaán durante una amplia cronología ${ }^{36}$.

\section{DATOS ARQUEOLÓGICOS}

Nuevos datos extraidos de las recientes excavaciones de Heracleópolis Magna, parecen sugerir sin embargo que la idea del recipiente cerámico como lugar óptimo para permanecer durante la experiencia de la muerte, pudo no haber quedado limitada en Egipto a los enterramientos de los individuos más jóvenes de la sociedad. Sin duda los cuerpos de los niños eran los más adecuados para dicha práctica funeraria, dado que en el repertorio de formas cerámicas egipcias no abundaban recipientes amplios que permitieran acomodar en su interior el cuerpo de un adulto.

No obstante, la intención de albergar simbólicamente a los muertos en el interior de vasijas de barro parece atestiguarse en los ritos funerarios de la necrópolis del TPI de Heracleópolis Magna ${ }^{37}$. La excavación de algunos enterramientos sencillos en dicha necrópolis, pertenecientes a un momento avanzado del TPI (finales del siglo vIII a.C.), ha permitido documentar la deposición de cuerpos inhumados protegidos a veces con cartonajes sencillos, acompañados de un exiguo ajuar, acomodados entre abundantes fragmentos de cerámica que en algún caso guardan un orden intencionado y que responden, en nuestra opinión, a un concepto espiritual concreto.

34 T.E. PeET- W.L.S. LOAT, The Cemeteries of Abydos III. 1912-1913. London 1913, págs. 1314 , PI. II, 8 , págs. 20-22.

35 W.M.F. PETRIE- J.G. DuCAN, op. cit., págs. 17, 43; E.C.M. van den Brink, Tombs and Burial Customs at Tell el-Dabá V. WIEN 1991, págs. 135 y sigtes; M. J. LóPEz Grande- F. Quesada SANZ, Excavaciones en Ehnasya El Medina (Heracleópolis Magna) (Informes Arqueológicos/ Egipto 2), Cap. IV. C, Lám. XXI, c. (en prensa).

${ }_{36}$ E.C.M. van den Brink, op. cit., págs. 28, 70-71.

${ }_{37}$ Acerca de la bibliografía sobre Heracleópolis Magna, véase: M.C. PÉrez Die- P. Vernus, Excavaciones en Ehnasya El Medina (Heracleópolis Magna). (Informes arqueológicos/Egipto 1). Madrid 1992, pág. 13, n. 1. 
Los fragmentos cerámicos asociados a dichos enterramientos suelen ser abundantes, si bien son pocas las veces en que pueden recomponerse los recipientes a los que pertenecieron ${ }^{38}$. Aparecen partes de distintos objetos cerámicos, a menudo muy imcompletos. Entre ellos a veces destacan los fragmentos de una tinaja de grandes dimensiones, fracturada en trozos grandes y ordenada en torno al difunto: la boca del recipiente yace en las inmediaciones del cráneo del fallecido; las asas aparecen situadas en la zona de los hombros del muerto; los galbos de las paredes del vaso, sobre el torso y bajo la espalda del individuo, y fragmentos de la base inestable del recipiente, en la zona próxima a los pies. Esa disposición de los fragmentos de un tipo concreto de grandes recipientes en torno al difunto se observaba sin dificultad en la excavación de los enterramientos M-406, localizado en el Heracleópolis Magna durante la campaña de excavación de 1989, en el sector denominado H.20, y M-414, localizado el mismo año en el mismo sector, de cuya excavación nos ocupamos personalmente. En otros enterramientos se han localizado fragmentos de ese mismo tipo de jarra, por ejemplo en M-782, excavado en el sector H.30 durante la campaña de 1990. Las vasijas a las que dichos fragmentos corresponden, son recipientes de base inestable y boca relativamente ancha, fabricados en arcilla aluvial (Fig. 1, 1-2). Morfológicamente parecen derivar de formas que se documentan al menos desde finales del IN o comienzos del TPI ${ }^{39}$, y que en ocasiones han sido documentadas como contenedores de inhumaciones infantiles, si bien su primer uso pudo ser doméstico ${ }^{40}$. Son recipientes adecuados para almacenar productos, y pudieron utilizarse como contenedores de agua. La porosidad de la arcilla aluvial con la que están fabricados mantendría el agua fresca, y la amplitud de la boca de la tinaja permitiría extraerla con un recipiente menor, en el que se podía beber $^{41}$.

Posiblemente las vasijas a las que se alude en la estela mencionada de Ramses $1{ }^{42}$ no fueron muy diferentes. Su función era específica: fueron fabricadas en el torno del alfarero para proveer de agua a los trabajadores

28 M.C. PÉREZ Die, Heracleópolis Magna durante el Tercer Periodo Intermedio. Madrid 1992, pág. 397.

39 W.M.F. Petrie- J.G. Duncan, op. cit., pág. 17, PI. XVIIA-2, 5; D.A. Aston, Egyptian Pottery from the Thirteen to the Seventh century B.C. Tentative footsteps in a forbidding terrain. (En prensa). Fig. 31. Agradecemos al autor su amabilidad al permitirnos manejar su manuscrito original aún inédito.

40 W.M.F. Petrie- J.G. Duncan, op. cit., pág. 17.

4. Tal y como se hace actualmente en Egipto a partir de los grandes recipientes denominados zir.

42 Véase nota 17 
de las canteras y evitar que en los días calurosos les faltara el agua fresca ${ }^{43}$. Aquellas jarras eran demoninadas $\underline{d} n t$, denominación que permite

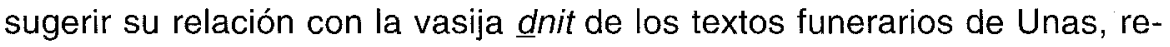
cipiente en cuyo interior el faraón permanecía el tiempo de la noche y que abandonaba al llegar la mañana.

Los recipientes heracleopolitanos cuyos fragmentos aparecen ordenados en torno, sobre y debajo de algunas inhumaciones, pudieron haber tenido un uso doméstico previo a su inclusión en la necrópolis. No podemos asegurarlo. Su forma y factura les hacen propicios para su utilización en el quehacer cotidiano. Quizá fue así, pero tuvieron además una proyección mayor: en algunos casos ocuparon un importante papel en el ritual funerario de al menos algunas personas que murieron en los últimos años del siglo vili a.C. en el entorno de Heracleópolis. Fueron usados en nuestra opinión como sarcórfagos ficticios de arcilla por aquellos que tenían poco que llevar a su tumba y que no poseían un receptáculo adecuado para permanecer durante las noches de la eternidad. Su uso en Heracleópolis quizá se debió a costrumbres locales, tal vez derivadas de la presencia de extranjeros en la zona, que fue frecuente ${ }^{44}$. Pero cabe pensar en la idea egipcia de la fertilidad del barro del Nilo, de su uso en los alfares del Valle y en el alfar del dios Jnum. Incluso cabe pensar en tradiciones egipcias muy antiguas, recogidas en los Textos de las Pirámides y vinculadas a los conceptos de regeneración y de eternidad que siempre estuvieron presentes en Egipto.

ASAE = Annales du Service des Antiquités de L'Egypte. Le Caire, 1900 y sigtes.

BAEO = Boletín de la Asociación Española de Orientalistas. Madrid.

JEA = Journal of Egyptian Antiquities. London, 1914 y sigtes.

JNES = Journal of Near Eastern Studies. Chicago, Illinois, 1942 y sigtes. $\mathrm{KIR}=$ K.A. Kitchen, Ramesside Inscriptions Historial and Biographical. 7 Vols. Oxford, 1968 y sigtes.

$\mathrm{LÄ} \quad=$ Lexikon der Ägyptologie. Wiesbaden.

PM = B. Porter - R.L.B. Moss, Topographical Bibliography of Ancient Egyptian Hieroglyphic Texts, Reliefs, and Paintings. 7 Vols. Oxford, 1927-52, (2. ${ }^{2}$ ed. 1960 y sigtes).

43 A. Hamada, ASAE 38 (1938) pág. 229; KRIII 362, 16-17.

44 M.C. PÉREZ DiE, «Fouilles recentes a Heracleopolis Magna», en A. Leahy (ed.) Libya and Egypt c. 1300-750 BC. London 1990, págs. 120 y sigtes. Entre la cerámica hallada en Heracleópolis se documentan algunas producciones procedentes del Levante Mediterráneo y de Chipre'. Véase: M.J. López Grande- F. Quesada SAnz, op. cit., Cap. IV. H. 
Pyr. = K. Sethe, Die Altaegyptischen Pyramidentexte. 4 Vols. Leipzig, $1908-1922$.

$\mathrm{VA}=$ Varia Aegyptiaca. San Antonio (Texas), 1985 y sigtes.

$\mathrm{Wb}=\mathrm{E}$. Erman und Hermann Grapow. Wöterbuch der Agyptischen Sprache. 5 Vols. Berlin - Leipzig, (ed.) 1957.

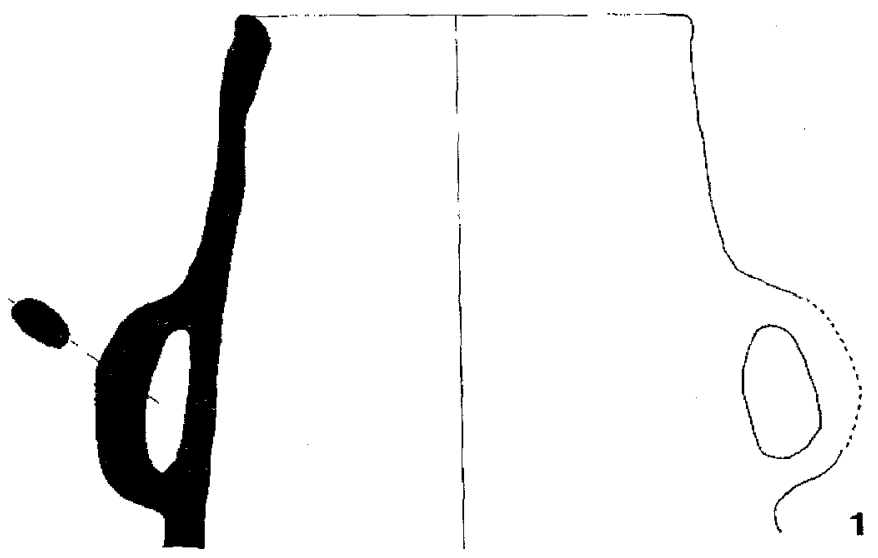

Fig. 1.1. Fragmento de recipiente cerámico hallado junto al cráneo del enterramiento M-414 localizado en Heraceópolis Magna, en 1989: HM-89/H.20

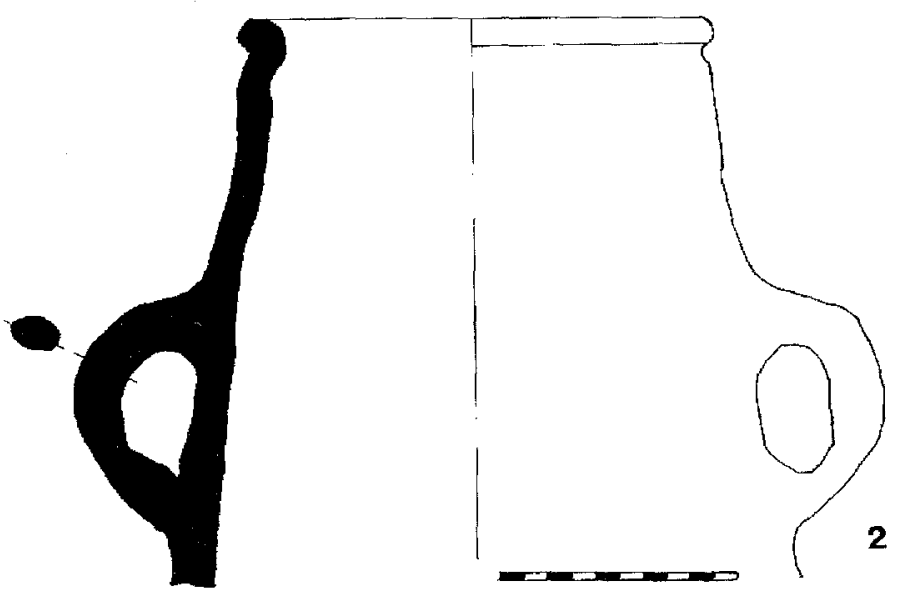

Fig. 1.2. Fragmento de recipiente cerámico hallado junto al cráneo del enterramiento M-406 localizado en Heracleópolis Magna, en 1989: HM-89/H.2O 